\title{
Research on the Cost of Human Resource Fine Management of Municipal Power Supply Enterprises
}

\author{
Li Tao, Wang Cong \\ North China Electric Power University, School of Economics and Management Beijing, China \\ 1t@ncepu.edu.cn,369486409@qq.com
}

\begin{abstract}
This paper introduces the concept of Activity-based Costing Management to analyze new division of human resource cost management control authority and the influencing factors in the degree of controllability, and makes a fine management plan for the provincial power grid company -the joint level, and the municipal power supply enterprises -the strategic level and operational level. According to the analysis, this paper strengthens the control human resource recruitment, training and performance evaluation, and makes up for problems of the traditional cost management model.

Index Terms - fine management, human resource cost, Activitybased cost management method
\end{abstract}

\section{Present situation of human resource costs management in municipal power supply enterprises}

The basic process of human resource management of municipal power supply enterprises includes five parts: the acquisition, development, using, protection and leaving. Corresponding to each business link, the municipal power supply enterprises human resource costs include acquisition cost, development cost, use cost, the cost of protection and the leaving cost, which depend on the basic business process of power supply enterprise human resource management.

In fact, municipal power supply enterprises human resource departments have no right to control basic salary, relevant national subsidies, the retirees' living subsidies and retirement payments. This paper will focus on three links: recruitment, training and performance evaluation.

\section{A. The shortcomings of human resource recruitment process management.}

On the one hand, the market mechanism of human resource recruitment has not been established. Municipal power supply enterprises refuse to receive excellent technical staff from other enterprises. Therefore, they cannot take advantage of such experienced workers with high technology level. On the other hand, municipal power supply enterprises are inadequate to take part in the process of human resource recruitment. They have no right to participate in the main recruitment processes, such as written examination and interview. Hiring rights are completely controlled by the provincial companies.

B. Municipal power supply enterprises are insufficient in human resource training process management.

For one thing, the budget control is not agile. The training funds are strictly used according to initial budgets. However, in the time that training programs are less or costs reduce caused by market price fluctuations, the training units perhaps will pay too much extra spendings. For another thing, the personnel department and finance department are lack of communication. These two departments belong to different functional departments; the poor communication often brings conflicts and contradiction. In addition, the way to pay training personnel salary is not reasonable. Municipal power supply enterprises always use outside consulting company as a medium to pay for internal technology experts' rewards, which produce extra cost expenses.

C. Municipal power supply enterprises are insufficient in human resource performance appraisal process.

The employees' salaries are closely linked with performance evaluation results. However, the biggest shortcoming is that the personnel department can only know whether each performance-based pay is issued fairly, but cannot get the knowledge of whether the assessment result is reasonable. Moreover, they do not know whether people who work harder and better will be paid more and reasonably. In this model, the personnel department can't guarantee that enterprise performance evaluation is scientific and play a role in motivating employees.

\section{Activity-based Costing Management of human resource costs in municipal power supply enterprises}

A. The brief introduction to Activity-based Costing Management of human resource costs in municipal power supply enterprises

According to the characteristics of human resource costs in power supply enterprises, the theory of Activity-based Costing Management must be used in fine human resource costs management. Activity-based Costing Management starts from five key activities of human resource managementrecruitment, training and development, using, security and leaving, then collects the costs or resources into activity cost pools which have been divided scientifically. For each activity center (operational level), some specialists should be set correspondingly in order to make actual control of those key activities which are related to the activity center. They are responsible for in the operational level of human resource costs fine management. In the end, the costs for each activity cost center will be allocated to final outputs, and costs occurred in the whole activity chain will be least. According to the analysis above, the theory of Activity-based Costing 
Management in power supply enterprises aims to ensure that human resource management would be operated normally and effectively, and that costs occurred in the whole activity chain should be least. As a result, the power enterprises should take a good consider of such big spendings like employees' wages, welfares, and all costs occurred in the whole activity chain. The activity chain of human resources management should be analyzed entirely and controlled finely. Fig. 1 is the process of Activity-based Costing Management of human resource costs in municipal power supply enterprise.

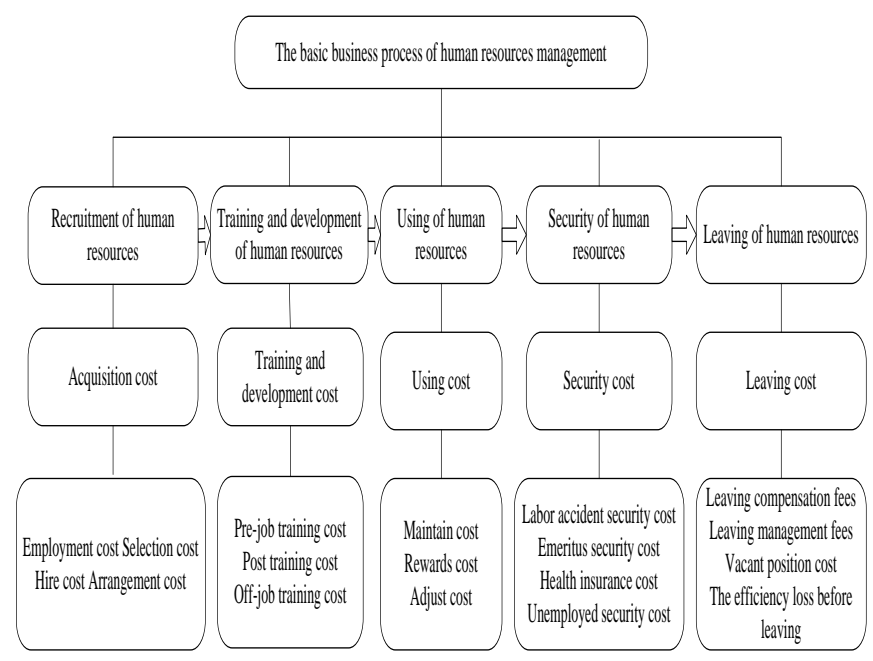

Fig. 1 Process of activity-based costing management of human resource costs in municipal power supply enterprises

\section{B. The authority division of human resource fine management and control in municipal power supply enterprises}

State Grid Corporation of China manages its junior provincial company and secondary branch in a way of 'human, finance, materials intensive management'. Municipal power supply enterprise doesn't have the right of human resources recruitment and performance evaluation standards. Therefore, the authority division of human resource fine management and control must be considered. In particular, in the authority division of human resource influencing factor fine management and control, provincial company is mainly responsible for the standard of salary, total wages control and staffs' recruitment and training, etc. Municipal power supply enterprise is mainly responsible for the salary payment, performance evaluation, drawing up recruitment requirements planning and employees' training of the branch level, etc.

\section{The controlled degree analysis of influencing factor in human resource costs in the municipal power supply enterprises}

We can take a deep research on influencing factors related to the change of human resource cost in the view of first level and second level. As the assets of enterprise, the majority amount of human resources has been identified in the forming point, which decides the expenses in the future several accounting period. But it cannot be ignored that human resources are different from other assets, which can be reduced and controlled effectively by scientific management and incentive policy. Table 1 is the controllable degree analysis of influencing factors in human resource costs in the view of municipal power supply enterprises and provincial company ( $\mathrm{RC}, \mathrm{NC}$ and $\mathrm{C}$ is short for relatively controllable, not controllable, and controllable ).

TABLE I The analysis of influencing factors and controllable degree in human resource costs

\begin{tabular}{|c|c|c|c|c|}
\hline \multirow{2}{*}{ Cost project } & \multicolumn{2}{|l|}{ Influencing factors } & \multicolumn{2}{|c|}{ Controllable degree analysis } \\
\hline & Level 1 & Level 2 & Provincial & Municipal \\
\hline \multirow{3}{*}{ Acquisition cost } & Number of recruitment & recruitment plan & $\mathrm{RC}$ & $\mathrm{C}$ \\
\hline & time and quantity of advertising & plan and method of advertising & $\mathrm{C}$ & $\mathrm{NC}$ \\
\hline & number of people for arrangement & position requires & $\mathrm{RC}$ & $\mathrm{C}$ \\
\hline \multirow{4}{*}{ Development cost } & number of training people & \multirow{4}{*}{ quality level of human resources; training plan } & $\mathrm{NC}$ & $\mathrm{C}$ \\
\hline & expenses for teaching materials & & $\mathrm{NC}$ & $\mathrm{C}$ \\
\hline & wages for teachers & & $\mathrm{NC}$ & $\mathrm{RC}$ \\
\hline & equipment fees & & $\mathrm{NC}$ & $\mathrm{C}$ \\
\hline \multirow{3}{*}{ Using cost } & number of workers & need of production and operation & $\mathrm{NC}$ & $\mathrm{NC}$ \\
\hline & average salary level & status of enterprise management & $\mathrm{RC}$ & $\mathrm{NC}$ \\
\hline & welfare and subsidy rates & relevant policies of nation and enterprise & $\mathrm{RC}$ & $\mathrm{NC}$ \\
\hline \multirow{3}{*}{ Protection cost } & retired number & retirement system of enterprise employee & $\mathrm{RC}$ & $\mathrm{NC}$ \\
\hline & unemployment & status of enterprise management & $\mathrm{RC}$ & $\mathrm{C}$ \\
\hline & way of safeguard & national laws and policies & $\mathrm{NC}$ & $\mathrm{NC}$ \\
\hline \multirow{3}{*}{ Leaving cost } & number of leaving people & status of enterprise operation & $\mathrm{NC}$ & $\mathrm{RC}$ \\
\hline & left compensation rate & $\begin{array}{l}\text { national relevant policies and the status of } \\
\text { enterprise operation }\end{array}$ & $\mathrm{NC}$ & $\mathrm{RC}$ \\
\hline & left loss rate & contribution level of staff job & $\mathrm{NC}$ & $\mathrm{C}$ \\
\hline
\end{tabular}




\section{Solution of prefecture-level power supply enterprises' human resources cost fine management}

A. The scheme for province power enterprise's docking layer of prefecture-level power supply enterprise's human resources cost fine management

1) Control the human resources recruitment's quality and cost : At present, every power supply branch company is only responsible for proposing company's staff recruitment demand plan, relevant recruitment activities are charged by provincial grid corporations. Provincial grid corporation should examine recruitment plan supplied by prefecture-level enterprise, investigate the number and structure of new employees, check on hiring process and employing staff of key positions, and communicate with prefecture-level enterprise's human resources department during the assessment process of new employees to avoid low efficiency caused by wrong selection.

2) Perfect the evaluation standard of staff's salary and performance: The establishment of personnel salary standard and performance evaluation standard, and the assessment of leader's work in prefecture-level city's branch power supply enterprise are charged by provincial grid corporation. Provincial grid company should comprehensively consider its own long-term development strategy with similar enterprise and competitor's salary level, make position analysis and evaluation about branch company, each leader's salary in branch should not only linked with performance evaluation closely, but also linked with the actual incentive effect of existing performance assessment system.

$B$. The scheme for strategic layer of prefecture-level power supply enterprise's human resources cost fine management

1) Ensure the rationality of human resource requirement plan: In order to realize the active control of subsequent related cost to human resource, prefecture-level power enterprise's human resources cost fine management strategy should control human resources work chain from the source of hiring needs. On one hand, they should make a reasonable forecast to the supply and demand of enterprise's human resource to make sure the reasonable personnel scale and structure. On the other hand, they also must analyze the personnel quantity, skill level, academic degree, business literacy every post needed to determine the actual demand of this year's personnel needed.

2) Education training of improving employee's cost consciousness. To carry out staff education training, prefecture-level power supply enterprise should improve the quality of staff from knowledge skills and cost consciousness. On one hand, the professional skills and knowledge level improve, the labor productivity and enterprises' comprehensive competitiveness improve, in the long run, the production cost can be reduced to a certain degree; on the other hand, being active to broadcast cost saving consciousness and scientific cost management to staff during the actual education training activities help enterprise form the culture and concept atmosphere of 'low cost'.

3) Pay attention to the effectiveness of employee performance evaluation incentive. In practice, prefecture-level power supply enterprise is responsible for implementation work of provincial staff salary standards and performance evaluation. Whether the performance assessment is effective is related to the role of corporation's incentive policy. Prefecture-level power supply enterprise need to establish strict and effective performance evaluation implementing measures to make sure there is no phenomenon of 'average' or 'much work is little, little work is much'.

\section{The scheme for operational layer of prefecture-level power supply enterprise's human resources cost fine management}

Human resources recruitment work should execute as interim measures for the administration of the graduates issued by province company strictly, as to specific recruitment plan, it is first made by related cost fine team (personnel) of branch human resources and management specialist from various departments, and then raised to be audited by strategic layer, finally, recruitment work should implemented by class organization. Therefore, in the recruitment link, operational layer should research and analyze the supply and demand of department's post, then raise to control layer, finally complete new employee recruitment plan by discussing and summary. At the same time, they should also organize branch new employee orientation and placement process. See specific fine management process for control layer and operation layer as table II.

TABLE II The design of human resource cost fine management's control point

\begin{tabular}{|c|c|c|}
\hline Recruitment link & Development training link & Performance evaluation link \\
\hline $\begin{array}{l}\text { Post demand analysis; } \\
\text { Collect analysis results of each } \\
\text { department's post demand; } \\
\text { Check post demand plan; } \\
\text { Verify post requirement plan; } \\
\text { Prepare yearly post demand plan; } \\
\text { Approve recruitment plan; } \\
\text { Province company review and reply, } \\
\text { then raise to State Grid; } \\
\text { State Grid approve; } \\
\text { Province company organize recruitment; } \\
\text { The analysis of actual recruitment } \\
\text { results }\end{array}$ & $\begin{array}{l}\text { Establish quota standard for every department's education training; } \\
\text { Issue training needs and budget; } \\
\text { Collect department's training demand plan and budget; } \\
\text { Audit business department's annual training demand and budget draft; } \\
\text { Organize the implementation of annual education training work; } \\
\text { Reimburse all actual expenses; } \\
\text { Audit the real development of training project and practical application } \\
\text { cost; } \\
\text { Evaluate department's training project implementation result of budget; } \\
\text { Review department's training projects and corresponding spending; } \\
\text { Examine implementation results of department's training project and } \\
\text { training; } \\
\text { Evaluate training effect and improve }\end{array}$ & $\begin{array}{l}\text { Establish quota standard for every department's education training; } \\
\text { Make performance evaluation index; } \\
\text { Audit evaluation index of department's employee; } \\
\text { Review the performance evaluation index system draft for every } \\
\text { department's principal and employee; } \\
\text { Organize performance assessment work to every department's } \\
\text { principal; } \\
\text { Organize the implementation of performance appraisal work to } \\
\text { department's employee; } \\
\text { Audit the fairness and efficiency of performance evaluation to the } \\
\text { chief of department; } \\
\text { Audit the fairness and efficiency of performance evaluation to the } \\
\text { employee of department }\end{array}$ \\
\hline
\end{tabular}




\section{Main advantages of prefecture-level power supply enterprise's human resources cost fine management}

This paper analyzes the project of prefecture-level power supply enterprise's human resources' relevant cost fine management under the guide of based cost concept, which has the following advantages compared with traditional models: first, by reviewing departments' annual training need and budget plan, examining and reviewing training project's implement and expenses' application to evaluate and provide improvements for training effect, we can change the problem of budget plan's unscientific, cost overrun and poor training effect under traditional human resource cost management. Second, by reviewing index's set of every department's performance evaluation and supervision department's principal's efficiency to employees' performance evaluation results, we can avoid affecting staff's work enthusiasm under the situation that the personnel department can't decide whether staff's performance evaluation result is reasonable in each unit and each office.

\section{References}

[1] Zhang Weizhen. A discuss on human resource management of municipal power supply enterprises. The Power Journal, 2006, 4: 562568.

[2] Lei Yutian. The thinking about some problems of human resource management of municipal power supply enterprises. The personnel labor education work, 2005(6): 42- 46.

[3] Meng Jinmei. A study on how to reduce human resource costs. Changchun: the Northeast normal university, 2008.

[4] Liu Heping. A research on human resources optimization of Inner Mongolia power supply enterprises. Beijing: North China electric power university, 2008. 